\title{
Isolation and Screening of Lignocellulose Degrading Fungi from Degraded Fruit Litter
}

\author{
Mamatha Pingili $^{1 *}$, Shailaja Raj Marla ${ }^{2}$, Ramakrishna Raparla ${ }^{1}$ and Sridhar Vanga ${ }^{1}$ \\ ${ }^{1}$ Vaageswari Institute of Pharmaceutical Sciences, Karimnagar, Telangana, India \\ ${ }^{2}$ St, Francis College for Women, Hyderabad, Telangana, India
}

*Corresponding author

\section{A B S T R A C T}

\section{Keywords}

Albizia lebbeck,

Biomass,

Cellulases,

Xylanases,

Ligninases.

Article Info

Accepted:

17 October 2017

Available Online:

10 December 2017
The objective of the study conducted was to screen \& isolate fungi capable of degrading the fruit litter of Albizia lebbeck. These fruit Biomass are often disposed by burning, which pose an environmental pollution problem. The fruit biomass can be potentially converted to various value added products like bio fuels, cheap energy sources for fermentation, improved animal feeds. Considering these facts the present work is focused on isolation of fruit litter degrading fungi. The fruit litter was allowed to degrade in specially made pits and soil sample from the degraded fruit was used for the isolation of fungi. Isolation was done by serial dilution method and direct inoculation method on czapekdox agar medium. 14 different fungi were isolated and they were tested qualitatively for their capability to release cellulases, xylanases and ligninases. Out of the 14 fungi isolated, Isolate 2(IS2) identified as Aspergillus niger had shown the potential of releasing of cellulases, xylanases and ligninases.

\section{Introduction}

Biomass is the mass of organic material from any biological material. A wide variety of biomass resources are available on earth for conversion in to bio products, which include whole plants, plant parts, plant constituents, processing by products, materials of marine origin and animal by-products, municipal and industrial wastes. These resources can be used to create new biomaterials (Howard et al., 2003), Mehdi Dashtban, et al., 2010). Lignocelluloses comprise the major structural component of woody plants and non woody plants such as grass. Lignocellulosic wastes are generated in large quantities by forestry and agricultural practices, paper and pulp industries, agro industries, timber industries which pose an environmental pollution problem. Such wastes are also present in municipal solid wastes and animal wastes (Howard et al., 2003; Mehdi Dashtban et al., 2010). Much of the lignocellulose waste is often disposed of by biomass burning, which is considered a global phenomenon. However, the huge amounts of residual plant biomass considered as waste can potentially be converted in to various value added products including biofuels, chemicals, cheap chemicals, cheap energy sources for fermentation, improved animal feeds and human nutrients (Howard et al., 2003). 
Lignocellulolytic enzymes also have significant potential applications in various industries including chemicals, fuel, food, brewery and wine, animal and feed, textile and laundry, pulp and paper and agriculture (Mehdi dashtban et al., 2009).

There are a number of studies with regard to wood and leaf litter decomposition, enzymes involved in the degradation process and recycling of nutrients, from different parts of the world. There are meagre studies with regard to fruit litter decomposition of albizia lebbeck and the enzymes involved in degradation process. The present investigation is undertaken to isolate fungi able to decompose fruit litter and the enzymes involved in the degradation of fruit litter of albizia lebbeck.

\section{Materials and Methods}

\section{Fruit material}

The fruit material was collected from Manakondur village, District Karimnagar, washed and shade dried.

\section{Isolation of lignocellulose degrading fungi}

The fruit litter was allowed to degrade in specially made pits. After a period of 3 months soil sample from the degraded fruit was collected and fungi were isolated by dilution plating technique on Czapekdox agar medium incorporated with chloramphenicol. The plates were incubated at RT $28+/-2^{0} \mathrm{C}$.

The plates were observed for growth daily and sub cultured on to fresh plates until pure fungal cultures were obtained. The pure cultures were maintained on slants by subculturing every four weeks. The isolated fungi were observed for their macroscopic and microscopic characteristics (Joseph C. Gilman).
Qualitative screening of the isolates for release of lignocellullolytic enzymes

\section{Composition of basal medium (BSM) used}

$\mathrm{C}_{4} \mathrm{H}_{12} \mathrm{~N}_{2} \mathrm{O}_{6}-5 \mathrm{~g} / \mathrm{l}, \quad \mathrm{KH}_{2} \mathrm{PO}_{4}-1 \mathrm{~g} / \mathrm{l}$, $\mathrm{MgSO}_{4} .7 \mathrm{H}_{2} \mathrm{O}-0.5 \mathrm{~g} / \mathrm{ml}$, Yeast extract $-0.1 \mathrm{~g} / 1$, $\mathrm{CaCl}_{2} \cdot 2 \mathrm{H}_{2} \mathrm{O}-0.001 \mathrm{~g} / \mathrm{l}$

Test for cellulase and xylanase activity (Stephen B. Pointing, 1999)

BSM incorporated with $2 \%$ carboxy methyl cellulose was used to grow the fungal isolates. The plates were stained with $1 \%$ Congo red solution followed by neutralization with $1 \mathrm{M}$ sodium chloride solution. Formation of clear zones around the colonies indicates the production of cellulase. BSM incorporated with $1 \%$ Xylan was used for the production of xylanases. The plates were flooded with iodine stain containing $1 \%$ iodine crystals, $2 \%$ KI. Based on the clearing zone xylanase producing organisms were screened. Xylan degradation around the colonies appears as yellow opaque area against a blue/reddish purple colour for undegraded xylan.

Test for Lignin degrading enzymes: (Stephen B. Pointing, 1999)

\section{Azure B agar clearance}

Lignin basal medium (LBM) was supplemented with $0.01 \% \mathrm{w} / \mathrm{v}$ Azure B and $1.6 \% \mathrm{w} / \mathrm{v}$ agar. $20 \% \mathrm{w} / \mathrm{v}$ Glucose was sterilized separately and added aseptically. The fungi was inoculated and incubated at $25^{\circ} \mathrm{C}$ in darkness. Clearance of blue coloured medium indicates production of LiP.

\section{Lignin agar}

LBM was supplemented with $0.25 \%$ w/v Lignin, inoculated with the fungus and incubated at $25^{\circ} \mathrm{C}$. After $5-10$ days the plates 
were flood with $1 \% \mathrm{w} / \mathrm{v}$ aqueous solution of fecl $_{3}$ and $\mathrm{K}_{3}\left[\mathrm{Fe}(\mathrm{CN})_{6}\right]$ prepared freshly before use. Phenols in undegraded lignin will stain blue green, with clear zones around colonies indicating oxidation of phenolic compounds.

\section{Tannic acid agar}

LBM was supplemented with separately sterilized $1 \% \mathrm{w} / \mathrm{v}$ aqueous tannic acid solution. After inoculation, incubated at $25^{\circ} \mathrm{C}$ in darkness. Lignin degrading enzyme production is indicated by brown oxidation zone around colonies.

\section{Guaicol agar}

LBM with $1 \%$ guaicol was inoculated with the fungus. Development of pinkish red colour around the colonies indicate the release of laccase enzyme.

\section{Identification of the selected fungi}

Out of the 14 isolates, IS2 which exhibited good cellulase, xylanase and ligninase activity was selected for further studies. Its identification was done by Lactophenol cotton blue staining (James and Natalie, 2001). A drop of the stain was placed on a clean slide and with the aid of a needle a small portion of the mycelium from the culture plate was removed and placed in the drop of stain. With the help of the needle the mycelium was spread and a coverslip was placed over the stain. The slide was then observed under the microscope. It was identified further by $18 \mathrm{~S}$ rRNA studies.

\section{Results and Discussion}

\section{Isolation of fungi}

A total of 14 fungi were isolated (IS1, IS2 IS3, IS4, IS5, IS6, IS7, IS8, IS9, IS10, IS11, IS12, IS13, IS14). The isolated fungi were maintained as pure cultures by sub culturing every four weeks.

\section{Qualitative screening of isolated fungi for lignocellulolytic activities}

Plate assays for all 14 isolates were carried out to know their potential cellulolytic, hemicellulolytic and ligninolytic activities. The isolates responded in different ways. Of all the isolates, IS2 had exhibited a promosing cellulolytic, hemicellulolytic and ligninolytic activity. Qualitative screening for cellulose activity was observed as clear zones around the colonies, when the isolates were grown on CMC agar and stained with congo red. Out of the 14 isolates IS1, IS2, IS5, IS11 (Fig. 1) had shown clear zones indicating the cellulase activity. Xylanase activity was due to the degradation of xylan in the medium by the fungi. The activity was observed by clear zones around the colonies up on staining with grams iodine. Isolates IS1, IS2, IS5, IS6, IS7, IS8, IS9 (Fig. 2) showed clear zones which confirms the release of xylanase enzyme. Four different qualitative tests using Lignin, tannic acid, guaicol and azure B to the basal medium were conducted to detect the release of various ligninases. Basal medium with guaicol is test specifically for detecting the release of laccase enzyme. No isolate exhibited laccase activity. On the LBM plates the undegraded lignin remains blue green with clear zones around colonies indicating oxidation of phenolic compounds. IS1, IS2, IS7, IS8, IS9, IS10 (Fig. 4) were positive for lignin degradation. Browning of the medium around the colony in tannic acid containing medium indicates degradation of lignin (Fig. 3). IS5, IS7, IS9, IS10 exhibited browning of medium (Fig. 4). In Azure method, decolorization of the dye azure $\mathrm{B}$ indicates the production of LiP and MnP. Dye decolourization was shown only by IS2 (Fig. 5a). IS 11 could not completely decolorize Azure B (Table 1). 
Table.1 Qualitative screening of the isolated fungi on CMC, lignin, Azure B, Guaicol, Tannic acid and xylan containing medium. (+) indicates release of the enzyme to degrade the respective substrate, (-) indicates no release of enzymes

\begin{tabular}{|c|c|c|c|c|c|c|}
\hline & CMC & Lignin & Azure B & Guaicol & Tannic acid & Xylan \\
\hline IS1 & + & + & - & - & - & + \\
\hline IS2 & + & + & + & - & - & + \\
\hline IS3 & - & - & - & - & - & - \\
\hline IS4 & - & - & - & - & - & - \\
\hline IS5 & + & - & - & - & + & + \\
\hline IS6 & - & - & - & - & - & + \\
\hline IS7 & - & + & - & - & + & + \\
\hline IS8 & - & + & - & - & - & + \\
\hline IS9 & - & + & - & - & + & + \\
\hline IS10 & - & + & - & - & + & - \\
\hline IS11 & + & - & - & - & - & - \\
\hline IS12 & - & - & - & - & - & - \\
\hline IS13 & - & - & - & - & - & - \\
\hline IS14 & - & - & - & - & - & - \\
\hline
\end{tabular}

Fig.1 Endoglucanase activity of IS2, IS5, $(\mathrm{a}, \mathrm{b})$ showing zones of clearance and IS12 (c) showing no activity

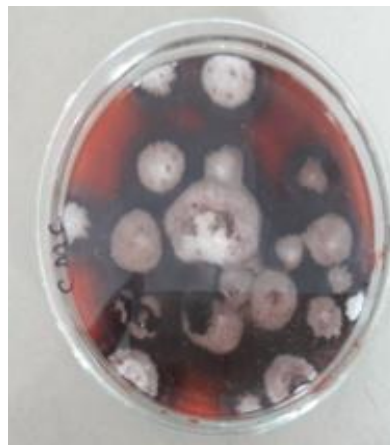

(a)

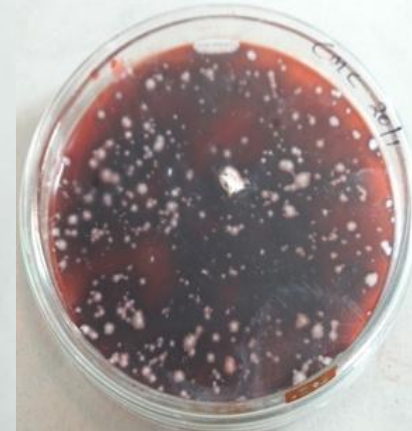

(b)

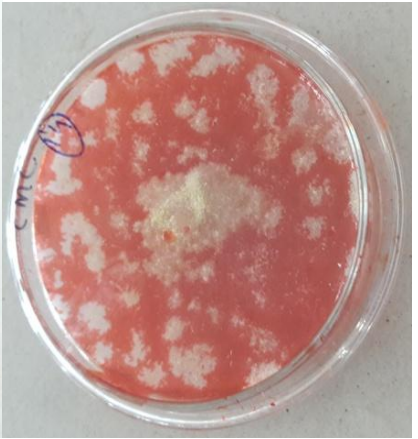

(c)

Fig.2 Ligninase activity of IS1, IS2 $(a, b)$ showing zones of clearance a b c

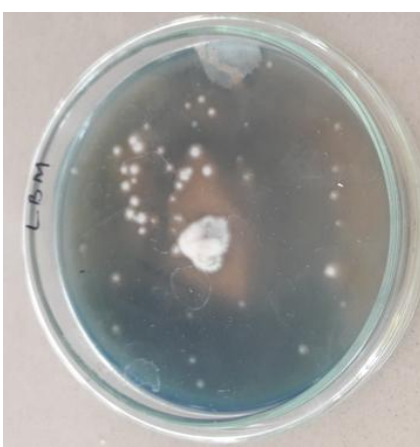

(a)

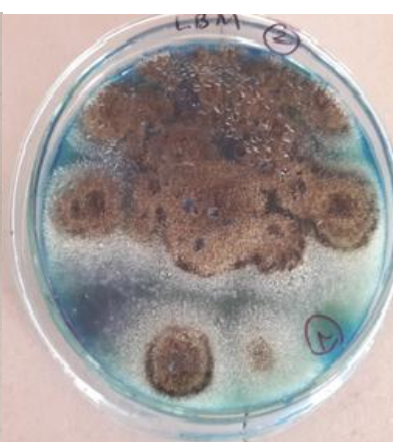

(b)

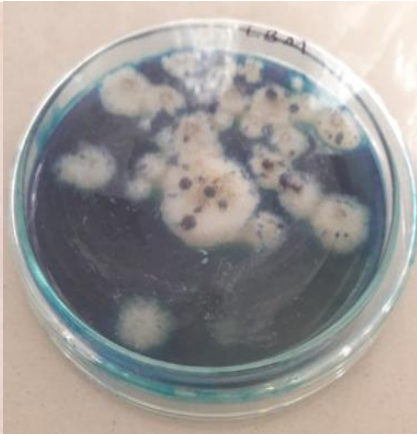

(c) 
Fig.3 Ligninase activity of IS10, IS7 (a, b) on tannic acid medium showing browning of the medium, IS 11 (c) showing no browning

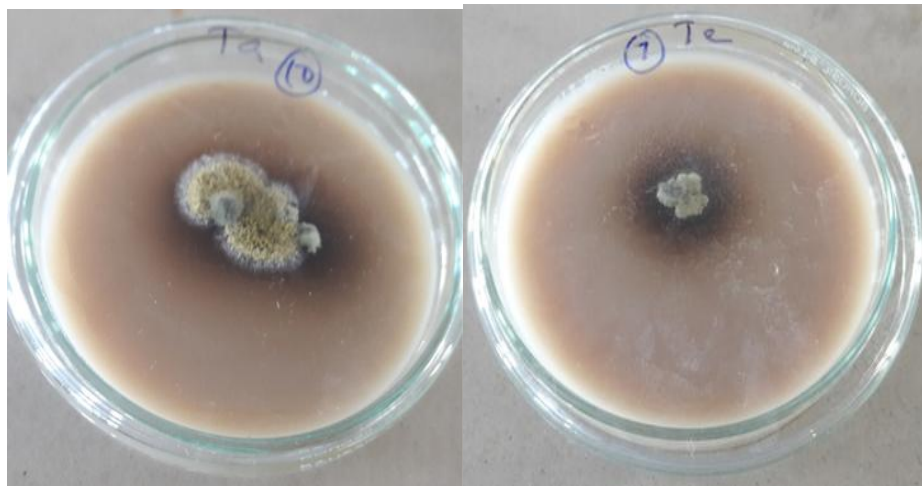

(a) (b)

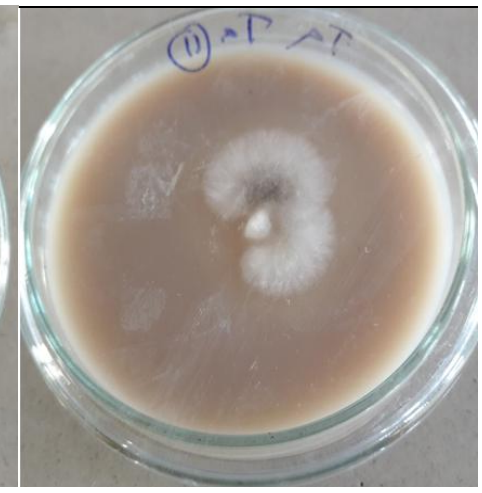

(c)

Fig.4 IS2(a) showing Azure B clearance, IS11 (b) showing partial clearance and IS5 showing no clearance of Azure B

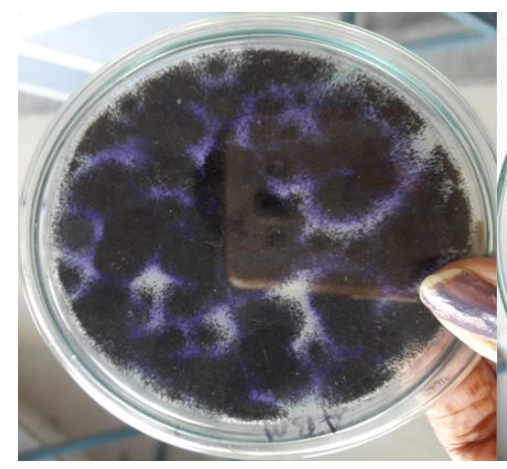

(a)

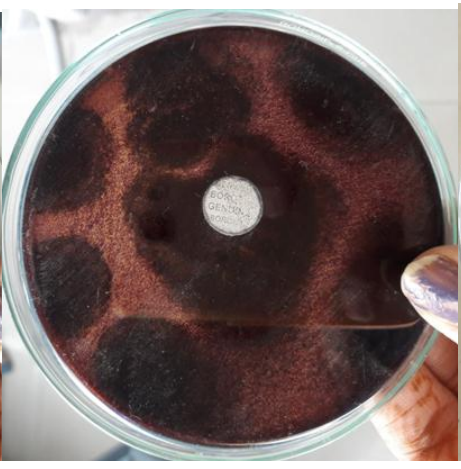

(b)

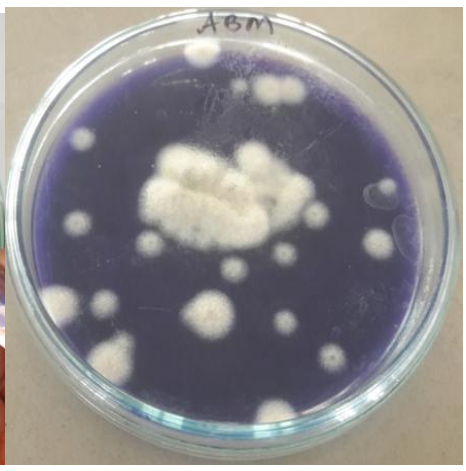

(c)

Fig.5 Xylanase activity of IS2 (a) showing zone of clearance and IS5(b) not exhibiting any clearance zone

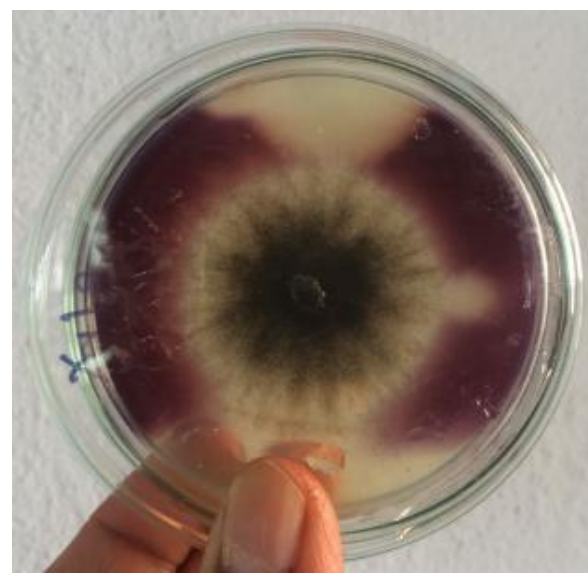

(a)

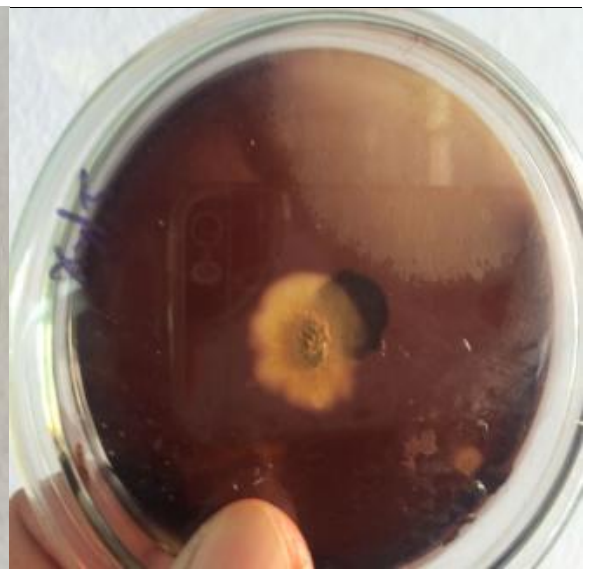

(b) 
Fig.6 Microscopic view of IS2 up on staining with Lactophenol cotton blue stain

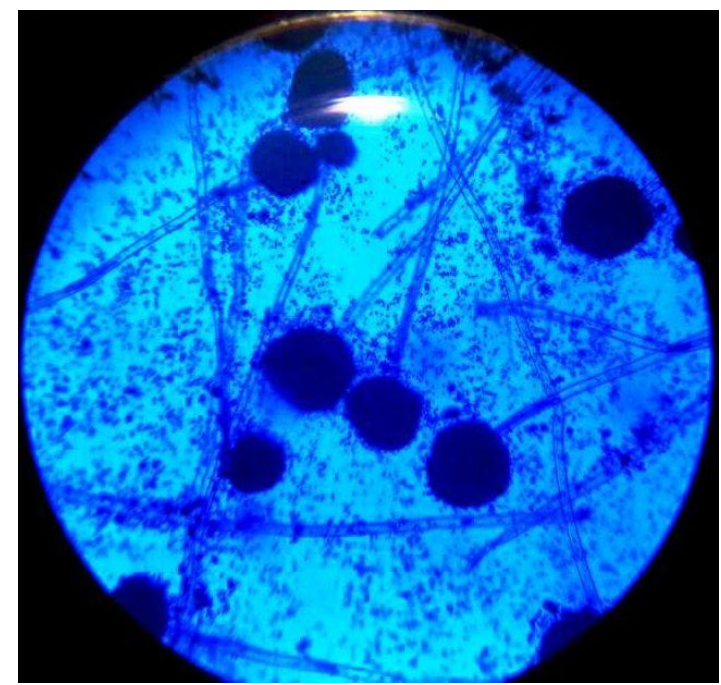

A partial degradation was indicated by development of pink colour of the plate (Fig. $5 \mathrm{~b}$ ) of the 14 isolates Isolate 2 (IS2) had shown a relatively good endoglucanase activity (Diameter of zone of clearance was more compared to other isolates positive for endoglucanase activity), Xylanase activity (Diameter of Zone of clearance is more) and peroxidase activity (Azure $B$ clearance). Hence IS2 can be exploited for further studies.

\section{Characterization and identification of Isolate 2}

Up on staining with Lactophenol cotton blue stain, IS2 was identified as Aspergillus niger. Identification of IS2 was also done by $18 \mathrm{~s}$ rRNA analysis. The screened IS2 was closely related to Aspergillus niger with $100 \%$ similarity.

There are several reports on the degradation of natural lignocellulosic substrates by Aspergillus niger. Aspergillus niger is already known to degrade sugarcane bagasse (Cunha et al., 2012; Praveen Kumar Reddy et al., 2015; Bhoosreddy, 2014), orange peels (Cunha et al., 2012; Amaeze et al., 2015), pine apple peels (Amaeze et al., 2015), coir waste (Soma Mrudula et al., 2011), rice bran (Praveen Kumar Reddy et al., 2015; Mahalakshmi et al., 2016), saw dust (Praveen Kumar Reddy et al., 2015; Bhoosreddy, 2014), ground nut shells (Praveen Kumar Reddy et al., 2015), wheat bran (Praveen Kumar Reddy, et al., 2015) and corn cobs (Praveen Kumar Reddy, et al., 2015; Bhoosreddy, 2014).

No reports are available on the lignocellulosic degradation of fruit litter of Albizia lebbeck Benth. Therefore Aspergillus niger can further be exploited for its capacity to degrade fruit litter of Albizia lebbeck.

As this fungi exhibited a good cellulase, xylanase and ligninase activity, quantitative studies for the production of these enzymes can be carried out by both submerged and solid state fermentation.

\section{Acknowledgment}

The authors are thankful to the management of Vaageswari institute of pharmaceutical sciences, Karimnagar, Telanagana for their support in carrying out this work. 


\section{References}

Abubakar, F.A, Oloyede, O.B (2013). Production and activity of cellulase from Aspergillus niger using rice bran and orange peel as substrates, International Journal of scientific research and management (IJSRM), 1(5): 285-291.

Amaeze N. J, Okoliegbe I N and Francis M E (2015). Cellulase production by Aspergillus niger and Saccharomyces cerevisiae using fruit wastes as substrates IJAMBR, (3): 3644.

Bhoosreddy. G. L,(2014): Comparative Study of Cellulase Production by Aspergillus niger and Trichoderma viride Using Solid State Fermentation On Cellulosic Substrates Corncob, Cane Bagasse and Sawdust, International Journal of Science and Research, 3(5): 324-326.

F.M. Cunha M.N. Esperança, T.C. Zangirolami, A.C. Badino, C.S. Farinas (2012). Sequential solid-state and submerged cultivation of Aspergillus niger on sugarcane bagasse for the production of cellulose. Bioresource Technology, 112: 270-274.

Howard R.L Abotsi E, Jansen van Rensburg E.L, Howard S (2003). Lignocellulose biotechnology: issues of bioconversion and enzyme production; African journal of Biotechnology, 2(12): 602-619.

James, G.C. and Natalie, S. (2001) Microbiology: A Laboratory Manual. 3rd Edition, Benjamin/Cummings Publishing Company, Redwood City, Pp. 211-223.

Joseph C. Gilman, A manual of soil fungi. Daya Publishing House, New Delhi, India. 1998

Lekh Ram, Kuldeep Kaur and Sandeep Sharma. (2014). Screening, isolation and characterization of cellulase producing micro-organisms from soil. International Journal of Pharmaceutical Science Invention; 3(3): 12-18.

L. G. A. Ong et al., (2004). Enzyme production and profile by Aspergillus niger during solid substrate fermentation using palm kernel cake as substrate, Applied Biochemistry and Biotechnology, 118(1-3): 73-79.

Mahalakshmi N, S. Jayalakshmi (2016). Cellulase production by Aspergillus niger under solid state fermentation using agro industrial wastes, Int. J. Adv. Multidiscip. Res. 3(2): 78-83.

Mehdi Dashtban Heidi Schraft, Tarannum A. Syed, Wensheng Qin, (2010). Fungal biodegradation and enzymatic modification of lignin; Int J Biochem Mol Bio, 1(1): 3650 .

Mehdi dashtban, Heidi Schraft, Wensheng Qin (2009); Fungal Bioconversion of Lignocellulosic Residues; opportunities and Perspectives; International journal of Biological Sciences, 5(6): 578-595.

Praveen Kumar Reddy G, G Narasimha, Kanderi Dileep Kumar, G Ramanjaneyulu, A Ramya, B S Shanti kumara and B Rajashekhar Reddy (2015). Cellulase production by Aspergillus niger on different natural lignocellulosic substrates, Int.J.Curr.Microbiol.App.Sci 4(4): 835-845

Soma Mrudula, Rangasamy Murugammal (2011): Production of cellulase by Aspergillus niger under submerged and solid state fermentation using coir waste as a substrate, Braz. J. Microbiol. vol. 42 no.3 July/Sept..

Stephen B. Pointing (1999). Qualitative methods for the determination of lignocellulolytic enzyme production by tropical fungi; Fungal Diversity 2.

\section{How to cite this article:}

Mamatha Pingili, Shailaja Raj Marla, Ramakrishna Raparla and Sridhar Vanga. 2017. Isolation and Screening of Lignocellulose Degrading Fungi from Degraded Fruit Litter. Int.J.Curr.Microbiol.App.Sci. 6(12): 2200-2206. doi: https://doi.org/10.20546/ijcmas.2017.612.252 